Acta Crystallographica Section D

\section{Biological Crystallography}

ISSN 0907-4449

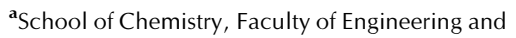
Physical Sciences, University of Manchester, Brunswick Street, Manchester M13 9PL, England, 'brystal and Structural Chemistry, Bijvoet Center for Biomolecular Research, Faculty of Science, Utrecht University, Padualaan 8, $584 \mathrm{CH}$ Utrecht, The Netherlands, and ${ }^{\mathrm{C}}$ Manchester Interdisciplinary Biocentre (MIB), University of Manchester, 131 Princess Street, Manchester M1 7DN, England

Correspondence e-mail:

john.helliwell@manchester.ac.uk

\title{
Structural studies of the effect that dimethyl sulfoxide (DMSO) has on cisplatin and carboplatin binding to histidine in a protein
}

The anticancer complexes cisplatin and carboplatin target the DNA major groove, forming intrastrand and interstrand crosslinks between guanine bases through their N7 atoms, causing distortion of the DNA helix and apoptotic cell death. A major side effect of these drugs is toxicity, which is caused via binding to many proteins in the body. A range of crystallographic studies have been carried out involving the cocrystallization of hen egg-white lysozyme (HEWL) as a test protein with cisplatin and carboplatin in aqueous and dimethyl sulfoxide (DMSO) conditions. Different cryoprotectants, glycerol and Paratone, were used for each of the cisplatin and carboplatin cocrystallization cases, while silicone oil was used for studies involving $\mathrm{N}$-acetylglucosamine (NAG). Both cisplatin and carboplatin do not bind to HEWL in aqueous media on the timescales of the conditions used here, but upon addition of DMSO two molecules of cisplatin or carboplatin bind either side of His15, which is the only His residue in lysozyme and is assumed to be an imidazolyl anion or a chemical resonance moiety, i.e. both imidazole $\mathrm{N}$ atoms are chemically reactive. To identify the platinum-peak positions in the 'with DMSO conditions', anomalous scattering maps were calculated as a cross-check with the $F_{\mathrm{o}}-F_{\mathrm{c}}$ OMIT maps. Platinum-occupancy $\sigma$ values were established using three different software programs in each case. The use of EVAL15 to process all of the diffraction data sets provided a consistent platform for a large ensemble of data sets for the various protein and platinum-compound model refinements with REFMAC5 and then SHELXTL. Overall, this extensive set of crystallization and cryoprotectant conditions allowed a systematic evaluation of cisplatin and carboplatin binding to lysozyme as a test protein via detailed X-ray crystal structure characterizations. DMSO is used as a super-solvent for drug delivery as it is deemed to cause no effect upon drug binding. However, these results show that addition of DMSO causes the platinum anticancer drugs to bind to HEWL. This effect should be considered in toxicity assessments of these drugs and perhaps more widely.

\section{Introduction}

DNA is the main biological target of the platinum anticancer drugs cisplatin and carboplatin. However, $90 \%$ of their reported binding is to plasma proteins (Fischer et al., 2008). Protein-platinum anticancer drug interactions have attracted interest as they are considered to be crucial for the pharmacokinetics, biodistribution, resistance processes and toxicity of these metallodrugs (Calderone et al., 2006; Casini et al., 2006; Casini, Mastrobuoni et al., 2007).
Received 7 October 2011

Accepted 15 February 2012

PDB References: HEWL, $4 \mathrm{dd} 0 ; 4 \mathrm{dd} 1 ; 4 \mathrm{dd} 2 ; 4 \mathrm{dd} 3$; 4dd4; 4dd6; 4dd7; 4dd9; $4 d d a ; 4 d d b ; 4 d d c$. 
Cisplatin exerts its anticancer effect by targeting the DNA major groove, forming intrastrand and interstrand cross-links between guanine bases via their N7 atoms (Kostova, 2006) and causing distortion of the DNA helix that leads to inhibition of DNA replication and transcription and triggers apoptotic cell death (Benedetti et al., 2002; Silverman et al., 2002). However, the toxicity caused by cisplatin and carboplatin could partly arise from binding to extracellular and intracellular proteins, forming drug-inactivation products (Sun et al., 2009). Binding affinity to cisplatin has been studied for a number of proteins, including a copper transporter (Arnesano \& Natile, 2008; Crider et al., 2010), a copper chaperone (Boal \& Rosenzweig, 2009), superoxide dismutase (Calderone et al., 2006; Casini et al., 2008), cytochrome $c$ (Casini et al., 2006; Casini, Gabbiani et al., 2007), human albumin (Ivanov et al., 1998), ubiquitin (Hartinger et al., 2006), glutathione (Zimmermann \& Burda, 2010) and hen egg-white lysozyme (HEWL; Casini, Mastrobuoni et al., 2007). The platinum ion is a soft ligand and makes favourable interactions with $\mathrm{S}$ atoms present in proteins through free methionine and cysteine side chains, forming strong bonds (Zimmermann \& Burda, 2010; Hahn et al., 2001). However, HEWL and superoxide dismutase have free histidine (His) residues which can coordinate the $\mathrm{Pt}$ ion through an $\mathrm{N}$ atom on the imidazole ring (Calderone et al., 2006; Casini, Mastrobuoni et al., 2007; Casini et al., 2008).

HEWL is a model protein for which the crystallization conditions and three-dimensional structure have been well documented. A study by $\mathrm{Li}$ (2006) reported a number of metal ions $\left(\mathrm{Ca}^{2+}, \mathrm{Ni}^{2+}\right.$ and $\left.\mathrm{Mn}^{2+}\right)$ bound to the active site of HEWL. Pt ions were not tested in this study, but it is possible that carboplatin could act as a sugar mimic (Fig. 1) and bind in the active site of HEWL. Casini, Mastrobuoni et al. (2007) undertook a crystallographic analysis of HEWL with both cisplatin and carboplatin using soaking of pre-grown 'native' lysozyme crystals. These crystallographic studies indicated that cisplatin was bound with an occupancy of around $50 \%$ to the $\mathrm{N}^{\delta}$ atom of the imidazole ring of His15, which is the only His residue in HEWL (PDB entry 2i6z). X-ray diffraction data for carboplatin were not deposited; however, using inductively coupled optical emission spectroscopy (ICP-OES) an occupancy of less than $15 \%$ was reported, in contrast to massspectrometric (MS) data which showed a significant mass increase upon carboplatin binding. The MS data also indicated the weak binding of a second cisplatin molecule which was not observed in the X-ray crystal structure [at the second $\mathrm{N}$ atom $\left(\mathrm{N}^{\varepsilon}\right)$ of the imidazole ring]. Dimethyl sulfoxide (DMSO) was present in the crystallization conditions used by Casini,

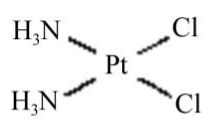

Cisplatin

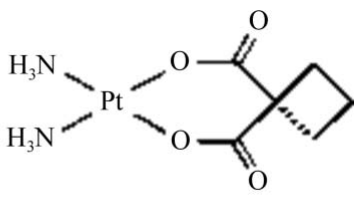

Carboplatin
Figure 1

Chemical structures of cisplatin and carboplatin.
Mastrobuoni et al. (2007) (see PDB entry 2i6z) and is observed bound at the lysozyme saccharide-binding site $C$ in the active site, coordinated by $\operatorname{Trp} 108$ and $\operatorname{Trp63}$, as previously reported (Jóhannesson et al., 1997). DMSO therefore acts as a sugarbinding mimic.

DMSO is a small polar molecule and can be used as an analgesic, a diuretic or as a penetrant carrier which readily crosses membranes without destroying their integrity (Pope \& Oliver, 1966; Jacob \& Wood, 1967; Pommier et al., 1988). A major use of DMSO is as a vehicle for drug administration (Dearman et al., 1998; Abedini et al., 2004; Axanova et al., 2005; Peaston \& Maddison, 2006; Huang et al., 2007). Cisplatin has previously been studied with DMSO in order to determine whether its anticancer effects are enhanced owing to the penetrant nature of DMSO (Pommier et al., 1988; Baliga et al., 1998). A study by Mickey et al. (1989) showed that using low doses of cisplatin resulted in no cytotoxic effect on a tumour cell; however, on the addition of DMSO it caused severe toxicity. Repeating this with the addition of furosemide resulted in the killing of tumour cells without the toxicity problems. An NMR study by Fischer et al. (2008) revealed the formation of a cisplatin-DMSO adduct within $15 \mathrm{~min}$ of dissolving cisplatin in DMSO and complete conversion within $1 \mathrm{~h}$, as observed previously (Kerrison \& Sadler, 1977). The DMSO molecule displaces one of the $\mathrm{Cl}$ atoms of cisplatin, as the $\mathrm{Pt}-\mathrm{S}$ interactions are favourable. This adduct can readily cross a membrane and accumulate in cells; however, its activity towards double-stranded DNA is abolished owing to the steric hindrance caused by DMSO, leading to increased toxicity. These findings lead to the conclusion that cisplatin should not be dissolved in DMSO for anticancer treatments owing to the rapid formation of the cisplatin-DMSO adduct (Kerrison \& Sadler, 1977; Feng et al., 2004; Fischer et al., 2008).

Casini, Mastrobuoni et al. (2007) published an important communication regarding the structural details of the binding of cisplatin to HEWL at $\mathrm{pH} 6.5$ using the crystal-soaking method and subsequent X-ray diffraction analysis. Our study builds on the work of Casini, Mastrobuoni et al. (2007), but uses cocrystallization rather than the crystal-soaking method. By harnessing the cocrystallization method, we have been able to crystallographically characterize carboplatin binding to HEWL. We have evaluated both aqueous and DMSO crystallization conditions. Furthermore, in order to assess the possible impact of differing cryoprotectants, two cryoprotectants were used in this study (glycerol and Paratone). The results obtained with both glycerol and Paratone in aqueous conditions confirm that they both mimic sugar binding in the active site. To assess whether cisplatin binding to His15 might cause a change in the active site, thus inhibiting the enzymatic reaction, HEWL was cocrystallized with its natural substrate $\mathrm{N}$-acetylglucosamine (NAG) and cisplatin to confirm whether any differences occurred upon binding of cisplatin. Overall, this extensive set of crystallization and cryoprotectant conditions, including the absence and presence of DMSO, allowed a systematic evaluation of the binding behaviour of cisplatin and carboplatin to HEWL as a test protein via detailed X-ray crystal structure characterizations. 
Table 1

The cocrystallization conditions used for all crystals are based on the general conditions published by Blundell \& Johnson (1976) using the batch crystallization method.

The protein concentration and in two cases temperature were varied to yield more optimal crystals both in number and quality; associated with this, the concentrations of cisplatin or carboplatin were varied to keep the molar ratio of each heavy-atom compound to protein the same.

\begin{tabular}{|c|c|c|c|c|c|}
\hline & \multicolumn{5}{|l|}{ HEWL cocrystallization } \\
\hline & $\begin{array}{l}\text { With cisplatin or carboplatin } \\
\text { in aqueous medium } \mathrm{pH} 4.7\end{array}$ & $\begin{array}{l}\text { With cisplatin or carboplatin } \\
\text { in DMSO medium } \mathrm{pH} 4.7\end{array}$ & $\begin{array}{l}\text { With cisplatin } \\
\text { in DMSO medium pH } 6.5\end{array}$ & With NAG & $\begin{array}{l}\text { With NAG and } \\
\text { cisplatin }\end{array}$ \\
\hline Cisplatin & $3 \mathrm{mg}(5 \mathrm{mM})$ & $3 \mathrm{mg}(10 \mathrm{~m} M)$ & $1.1 \mathrm{mg}(1.8 \mathrm{~m} M)$ & - & $1.1 \mathrm{mg}(1.8 \mathrm{mM})$ \\
\hline Carboplatin & $3.7 \mathrm{mg}(5 \mathrm{mM})$ & $3.7 \mathrm{mg}(10 \mathrm{~m} M)$ & - & - & - \\
\hline DMSO & - & $75 \mu \mathrm{l}(1 \mathrm{mM})$ & $75 \mu \mathrm{l}(1 \mathrm{~m} M)$ & - & $75 \mu \mathrm{l}(1 \mathrm{~m} M)$ \\
\hline Sodium acetate $(0.04 M)$ & $1 \mathrm{ml}$ & $462.5 \mu \mathrm{l}$ & $462.5 \mu \mathrm{l}$ & $1 \mathrm{ml}$ & $462.5 \mu \mathrm{l}$ \\
\hline Temperature (K) & 295 & 295 & 277 & 295 & 277 \\
\hline Time for crystallization (d) & 3 & 3 & 8 & 7 & 6 \\
\hline
\end{tabular}

Table 2

Data-collection strategy used for the Bruker PLATINUM135 CCD detector.

\begin{tabular}{lcc}
\hline & Swing around $\varphi\left(^{\circ}\right)$ & Sweep $\left(^{\circ}\right)$ \\
\hline \multirow{2}{*}{$4 \mathrm{dd} 1$} & 20 & $307.0 \varphi$ \\
$4 \mathrm{dd} 4$ & -15.5 & $202.0 \varphi$ \\
& -8.0 & $38.0 \omega$ \\
& 12.0 & $35.0 \omega$ \\
& 22.0 & $52.0 \omega$ \\
$4 \mathrm{dd} 6$ & 22.0 & $63.0 \omega$ \\
& 0 & $360.0 \varphi$ \\
$4 \mathrm{dd} 7$ & 20 & $360.0 \varphi$ \\
& 0 & $31.0 \omega$ \\
& 0 & $180.0 \omega$ \\
$4 \mathrm{ddc}$ & 0 & $360.5 \varphi$ \\
& 20 & $360.5 \varphi$ \\
& 0 & $360.0 \varphi$ \\
& 20 & $360.0 \varphi$ \\
\hline
\end{tabular}

\section{Materials and methods}

\subsection{Materials}

Cisplatin, HEWL, glycerol and NAG were purchased from Sigma-Aldrich UK. Carboplatin was purchased from Calbiochem USA, DMSO from Cambridge Isotope Laboratory, UK and sodium chloride $(\mathrm{NaCl})$ from Fisher Scientific, UK. Sodium acetate and acetic acid (AnalaR grade) were purchased from BDH, USA. Paratone and silicone oil were purchased from Molecular Dimensions, UK.

\subsection{Cocrystallizations}

Table 1 summarizes the conditions used in each case; glycerol and Paratone were used as cryoprotectants for all crystals except for HEWL with NAG and HEWL with NAG and cisplatin, for which silicone oil was used.

\subsection{X-ray data collection, structure solution and refinement}

Of the 11 crystals studied, data for six $(4 \mathrm{dd} 0,4 \mathrm{dd} 2,4 \mathrm{dd} 3$, $4 \mathrm{dd} 9$, 4dda and 4ddb; the crystals are named according to the PDB entry for the structure obtained) were collected on a Rigaku R-AXIS IV image-plate detector and data for the remaining five (4dd1, 4dd4, 4dd6, 4dd7 and 4ddc) were collected on a Bruker PLATINUM135 CCD detector both using an X-ray wavelength of $1.5418 \AA$ and a sample temperature of $100 \mathrm{~K}$.

The R-AXIS IV image-plate detector was positioned between 100 and $200 \mathrm{~mm}$ away from the crystal (Tables 3, 4 and 5) with an exposure time of between 3 and $10 \mathrm{~min}$ for each diffraction image; a $360^{\circ}$ rotation range was measured at an angular width of $1^{\circ}$, with the exceptions of $4 \mathrm{dd} 3$ and $4 \mathrm{dda}$, for which $272^{\circ}$ and $181^{\circ}$ rotation ranges were measured, respectively.

For the Bruker PLATINUM135 CCD detector, a strategy program was used to obtain the maximum information from each crystal in the measurement time. Table 2 summarizes the detector swing angles and the sweep of data collected for each data set.

All data sets were processed using EVAL15 (Schreurs et al., 2010 ) to rule out any software dependencies (Tables 3, 4 and $5)$ such as on average atomic $B$ factors. Each data set was also processed via MOSFLM (Leslie \& Powell, 2007); the R-AXIS data sets via its internal software $d^{*} T R E K$ and the Bruker data sets via PROTEUM2.

All structures were solved using molecular replacement with Phaser (McCoy et al., 2007) and restrained refinement with TLS in REFMAC5 (Vagin \& Teplyakov, 2010) in CCP4i, using the lysozyme structure $2 \mathrm{w} 1 \mathrm{y}$ as the molecular search model (Cianci et al., 2008). Model building, adjustment and refinement were carried out using the Coot (Emsley \& Cowtan, 2004) molecular-graphics program and REFMAC5 (Vagin \& Teplyakov, 2010) in $C C P 4 i$, respectively. Ligandbinding occupancies were calculated using SHELXTL (Sheldrick, 2008). Crystallographic and refinement parameters are summarized in Tables 3, 4 and 5 for all data sets.

It is difficult to offer a consistent resolution-cutoff criterion owing to differing detector apertures and average data $I / \sigma(I)$ effects. Instead, in a companion paper (Tanley et al., 2012) raw diffraction data images will be made available in addition to the PDB depositions listed in this article via their DOIs and our local University data archive. In any case, the resolution 
Table 3

X-ray crystallographic data processed via EVAL15 and refinement statistics for all cisplatin cocrystallizations in aqueous and DMSO media using glycerol or Paratone as the cryoprotectant at $\mathrm{pH} 4.7$ and 6.5 .

\begin{tabular}{|c|c|c|c|c|c|}
\hline & $\begin{array}{l}\text { Cisplatin/aqueous/ } \\
\text { glycerol pH } 4.7 \text { (4dd0) }\end{array}$ & $\begin{array}{l}\text { Cisplatin/aqueous/ } \\
\text { Paratone pH } 4.7 \text { (4dd1) }\end{array}$ & $\begin{array}{l}\text { Cisplatin/DMSO/ } \\
\text { glycerol pH } 4.7 \text { (4dd4) }\end{array}$ & $\begin{array}{l}\text { Cisplatin/DMSO/ } \\
\text { Paratone pH } 4.7 \text { (4dd6) }\end{array}$ & $\begin{array}{l}\text { Cisplatin/DMSO/ } \\
\text { Paratone pH } 6.5 \text { (4ddb) }\end{array}$ \\
\hline \multicolumn{6}{|l|}{ Data reduction } \\
\hline Space group & $P 4_{3} 2_{1} 2$ & $P 2_{1} 2_{1} 2_{1}$ & $P 4_{3} 2{ }_{1} 2$ & $P 4_{3} 2_{1} 2$ & $P 4_{3} 2{ }_{1} 2$ \\
\hline Unit-cell parameters $\left(\AA,^{\circ}\right)$ & $\begin{array}{l}a=b=78.69 \\
c=36.90 \\
\alpha=\beta=\gamma=90.0\end{array}$ & $\begin{array}{l}a=77.88, b=78.70 \\
\quad c=37.07 \\
\alpha=\beta=\gamma=90.0\end{array}$ & $\begin{array}{l}a=b=78.83 \\
\quad c=37.02 \\
\alpha=\beta=\gamma=90.0\end{array}$ & $\begin{array}{l}a=b=78.02 \\
\quad c=37.07 \\
\alpha=\beta=\gamma=90.0\end{array}$ & $\begin{array}{l}a=b=79.64 \\
c=37.02 \\
\alpha=\beta=\gamma=90.0\end{array}$ \\
\hline Molecular mass (Da) & 14700 & 14700 & 14700 & 14700 & 14700 \\
\hline Molecules per asymmetric unit & 1 & 2 & 1 & 1 & 1 \\
\hline Detector & R-AXIS IV & Bruker & Bruker & Bruker & R-AXIS IV \\
\hline Crystal-to-detector distance (mm) & 100 & $60 \dagger$ & $50 \dagger$ & $60 \dagger$ & 200 \\
\hline Observed reflections & 336926 & 131592 & 173061 & 272733 & 79530 \\
\hline Unique reflections & 13312 & 25216 & 11859 & 10901 & 3234 \\
\hline Resolution (̊) & 19.67-1.70 (1.76-1.70) & $18.04-1.70(1.76-1.70)$ & $18.92-1.70(1.76-1.70)$ & $18.92-1.70(1.76-1.70)$ & $30.94-2.50(2.58-2.50)$ \\
\hline Completeness (\%) & $99.9(100)$ & $97.7(92.2)$ & $88.6(100)$ & $82.8(100)$ & $72.0(100)$ \\
\hline$R_{\text {merge }}$ & $0.104(0.640)$ & $0.060(0.200)$ & $0.079(0.313)$ & $0.067(0.306)$ & $0.136(0.528)$ \\
\hline$\langle I / \sigma(I)\rangle$ & $22.69(4.4)$ & $16.9(5.0)$ & $22.2(5.2)$ & $35.1(8.1)$ & $22.6(6.1)$ \\
\hline Multiplicity & $25.3(25.8)$ & $5.4(4.4)$ & $14.6(9.1)$ & $25.0(18.0)$ & $24.6(24.5)$ \\
\hline Cruickshank DPI $(\AA ̊ \cap)$ & 0.1324 & 0.1277 & 0.1779 & 0.315 & 0.584 \\
\hline Average $B$ factor $\left(\AA^{2}\right)$ & 18.5 & 15.6 & 14.0 & 14.6 & 17.8 \\
\hline \multicolumn{6}{|l|}{ Refinement } \\
\hline$R$ factor $/ R_{\text {free }}(\%)$ & $18.7 / 23.6$ & $18.9 / 22.6$ & $20.2 / 25.9$ & $21.7 / 26.7$ & $21.4 / 27.9$ \\
\hline$R$ factor all (\%) & 18.9 & 19.1 & 20.5 & 21.9 & 21.6 \\
\hline R.m.s.d. bond lengths $(\AA)$ & 0.017 & 0.020 & 0.018 & 0.018 & 0.007 \\
\hline R.m.s.d. angles $\left({ }^{\circ}\right)$ & 1.92 & 2.05 & 1.86 & 2.42 & 1.17 \\
\hline \multicolumn{6}{|l|}{ Ramachandran values (\%) } \\
\hline Most favoured & 96.85 & 96.06 & 96.85 & 97.64 & 92.13 \\
\hline Additional allowed & 3.15 & 3.94 & 3.15 & 2.36 & 7.87 \\
\hline Disallowed & 0 & 0 & 0 & 0 & 0 \\
\hline
\end{tabular}

$\dagger$ The distance from the face of the detector to the phosphor plane is an additional $6.6 \mathrm{~mm}$.

Table 4

X-ray crystallographic data processed via EVAL15 and refinement statistics for all carboplatin cocrystallizations in aqueous and DMSO media with glycerol or Paratone as the cryoprotectant at $\mathrm{pH} 4.7$.

\begin{tabular}{|c|c|c|c|c|}
\hline & $\begin{array}{l}\text { Carboplatin/aqueous/ } \\
\text { glycerol pH } 4.7 \text { (4dd2) }\end{array}$ & $\begin{array}{l}\text { Carboplatin/aqueous/ } \\
\text { Paratone pH } 4.7 \text { (4dd3) }\end{array}$ & $\begin{array}{l}\text { Carboplatin/DMSO/ } \\
\text { glycerol pH } 4.7 \text { (4dd7) }\end{array}$ & $\begin{array}{l}\text { Carboplatin/DMSO/ } \\
\text { Paratone } \mathrm{pH} 4.7 \text { (4dd9) }\end{array}$ \\
\hline \multicolumn{5}{|l|}{ Data reduction } \\
\hline Space group & $P 4_{3} 2_{1} 2$ & $P 4_{3} 2_{1} 2$ & $P 4_{3} 2_{1} 2$ & $P 4_{3} 2_{1} 2$ \\
\hline Unit-cell parameters $\left(\AA,^{\circ}\right)$ & $\begin{array}{c}a=b=78.91, c=36.99 \\
\alpha=\beta=\gamma=90.0\end{array}$ & $\begin{array}{c}a=b=78.54, c=37.36 \\
\alpha=\beta=\gamma=90.0\end{array}$ & $\begin{array}{c}a=b=78.82, c=37.03 \\
\alpha=\beta=\gamma=90.0\end{array}$ & $\begin{array}{c}a=b=78.04, c=36.96 \\
\alpha=\beta=\gamma=90.0\end{array}$ \\
\hline Molecular mass (Da) & 14700 & 14700 & 14700 & 14700 \\
\hline Molecules per asymmetric unit & 1 & 1 & 1 & 1 \\
\hline Detector & R-AXIS IV & R-AXIS IV & Bruker & R-AXIS IV \\
\hline Crystal-to-detector distance (mm) & 120 & 120 & $50 \dagger$ & 120 \\
\hline Observed reflections & 271407 & 239297 & 500514 & 296297 \\
\hline Unique reflections & 14462 & 13144 & 15970 & 15451 \\
\hline Resolution ( & $19.73-1.55(1.60-1.55)$ & $31.01-1.70(1.76-1.70)$ & $20.67-1.60(1.65-1.60)$ & $31.01-1.70(1.76-1.70)$ \\
\hline Completeness $(\%)$ & $82.6(53.0 \ddagger)$ & $98.1(82.9)$ & $99.9(99.9)$ & $98.9(89.7)$ \\
\hline$R_{\text {merge }}$ & $0.063(0.456)$ & $0.062(0.314)$ & $0.057(0.179)$ & $0.047(0.154)$ \\
\hline$\langle I / \sigma(I)\rangle$ & $30.1(2.1)$ & $32.6(7.2)$ & $42.5(7.0)$ & $42.8(6.6)$ \\
\hline Multiplicity & $18.8(4.2)$ & $18.3(13.2)$ & $31.4(9.4)$ & $19.2(4.5)$ \\
\hline Cruickshank DPI (Å) & 0.117 & 0.126 & 0.106 & 0.119 \\
\hline Average $B$ factor $\left(\AA^{2}\right)$ & 23.0 & 17.8 & 13.6 & 18.6 \\
\hline \multicolumn{5}{|l|}{ Refinement } \\
\hline$R$ factor $/ R_{\text {free }}(\%)$ & $20.0 / 24.5$ & $19.2 / 23.5$ & $18.3 / 22.3$ & $20.4 / 23.5$ \\
\hline$R$ factor all (\%) & 20.2 & 19.4 & 18.5 & 20.5 \\
\hline R.m.s.d. bonds ( & 0.019 & 0.019 & 0.020 & 0.018 \\
\hline R.m.s.d. angles $\left({ }^{\circ}\right)$ & 2.07 & 1.91 & 2.07 & 1.89 \\
\hline \multicolumn{5}{|l|}{ Ramachandran values (\%) } \\
\hline Most favoured & 97.64 & 96.06 & 97.64 & 96.85 \\
\hline Additional allowed & 2.36 & 3.94 & 2.36 & 3.15 \\
\hline Disallowed & 0 & 0 & 0 & 0 \\
\hline
\end{tabular}

$\dagger$ The distance from the face of the detector to the phosphor plane is an additional $6.6 \mathrm{~mm}$. $\neq$ The next resolution shell (1.67-1.60 A) has a high completeness of $88.4 \%$.

limits are reasonably similar, except for two crystals (4dda and $4 \mathrm{ddb}$ ) for which the resolution is limited by crystal disorder. In the highest resolution shell the average unmerged $I / \sigma(I)$ varies between 0.9 and 3.5 . 
Table 5

X-ray crystallographic data processed via EVAL15 and refinement statistics for HEWL cocrystallized with NAG and HEWL cocrystallized with NAG, cisplatin and 7.5\% DMSO using silicone oil as cryoprotectant.

\begin{tabular}{|c|c|c|}
\hline & $\begin{array}{l}\text { HEWL/NAG } \\
\text { (4dda) }\end{array}$ & $\begin{array}{l}\text { HEWL, NAG, } \\
\text { cisplatin and } 7.5 \% \\
\text { DMSO (4ddc) }\end{array}$ \\
\hline \multicolumn{3}{|l|}{ Data reduction } \\
\hline Space group & $P 4_{3} 2_{1} 2$ & $P 2_{1} 2_{1} 2_{1}$ \\
\hline Unit-cell parameters $\left(\AA{ }^{\circ},{ }^{\circ}\right)$ & $\begin{array}{l}a=b=78.37 \\
\quad c=36.58 \\
\alpha=\beta=\gamma=90.0\end{array}$ & $\begin{array}{l}a=77.94, \\
\quad b=79.09, \\
c=36.98, \\
\alpha=\beta=\gamma=90.0\end{array}$ \\
\hline Molecular mass $(\mathrm{Da})$ & 14700 & 14700 \\
\hline Molecules per asymmetric unit & 1 & 2 \\
\hline Detector & R-AXIS IV & Bruker \\
\hline Crystal-to-detector distance $(\mathrm{mm})$ & 135 & $60 \dagger$ \\
\hline Observed reflections & 49543 & 329619 \\
\hline Unique reflections & 4120 & 21884 \\
\hline Resolution (§) & $\begin{array}{l}19.59-2.40 \\
\quad(2.48-2.40)\end{array}$ & $\begin{array}{l}19.16-1.80 \\
\quad(1.86-1.80)\end{array}$ \\
\hline Completeness (\%) & $85.3(100)$ & $99.9(100)$ \\
\hline$R_{\text {merge }}$ & $0.147(0.607)$ & $0.079(0.213)$ \\
\hline$\langle I / \sigma(I)\rangle$ & $13.6(4.02)$ & $22.9(4.2)$ \\
\hline Multiplicity & $12.1(12.8)$ & $15.1(5.6)$ \\
\hline Cruickshank DPI $(\AA)$ & 0.806 & 0.1682 \\
\hline Average $B$ factor $\left(\AA^{2}\right)$ & 29.5 & 16.2 \\
\hline \multicolumn{3}{|l|}{ Refinement } \\
\hline$R$ factor $/ R_{\text {free }}(\%)$ & $20.0 / 28.5$ & $21.8 / 25.5$ \\
\hline$R$ factor all (\%) & 20.4 & 21.9 \\
\hline R.m.s.d. bonds $(\AA)$ & 0.013 & 0.018 \\
\hline R.m.s.d. angles $\left({ }^{\circ}\right)$ & 2.38 & 1.82 \\
\hline \multicolumn{3}{|l|}{ Ramachandran values (\%) } \\
\hline Most favoured & 97.64 & 96.85 \\
\hline Additional allowed & 1.57 & 3.15 \\
\hline Disallowed & 0.79 & 0 \\
\hline
\end{tabular}

$\dagger$ The distance from the face of the detector to the phosphor plane is an additional $6.6 \mathrm{~mm}$.

\section{Results}

\subsection{Binding of cisplatin and carboplatin in DMSO media}

3.1.1. Cisplatin and carboplatin details. In both the cisplatin and carboplatin cases, one molecule was coordinated by the $\mathrm{N}^{\delta}$ and $\mathrm{N}^{\varepsilon}$ atoms (which we call 'right-hand' and 'lefthand' sites) of the imidazole ring of His15. This was true for both cryoprotectants (Fig. 2). In the case of carboplatin only the $\mathrm{Pt}$ ion and the two $\mathrm{N}$ atoms could be modelled based on the electron-density maps (Figs. $2 c$ and $2 d$ ); the cyclobutanedicarboxylate (CBDC) moiety could not be modelled owing to an absence of electron density. The CBDC moiety acts as a leaving group, activating carboplatin to bind to DNA and thus giving rise to the possibility of CBDC release upon binding of carboplatin to the $\mathrm{N}$ atoms of His15. With regard to cisplatin binding (Figs. $2 a, 2 b$ and $2 e$ ), the number of $\mathrm{Cl}$ and $\mathrm{N}$ atoms bound to the $\mathrm{Pt}$ ion varies based on the electron density observed for each data set.

To compare the crystal-soaking method used by Casini, Mastrobuoni et al. (2007) and the cocrystallization method used in this study, HEWL was cocrystallized with cisplatin at $\mathrm{pH} 6.5$ in DMSO conditions. However, owing to the differences in crystal-growth time, a direct comparison is not suggested. Fig. 2(e) confirmed that one molecule of cisplatin was again coordinated to both the $\mathrm{N}^{\delta}$ and $\mathrm{N}^{\varepsilon}$ atoms of the imidazole ring of His15 at $\mathrm{pH} 6.5$, in contrast to Casini, Mastrobuoni et al. (2007) who only observed binding at the $\mathrm{N}^{\delta}$ atom of His15 in their crystal structure, although their ESIMS study indicated a doubly-platinated species. The different $\mathrm{pH}$ conditions used ( $\mathrm{pH} 4.7$ and 6.5) resulted in no differences in protein conformation in the presence of $\mathrm{Pt}$ ions based on using $L S Q K A B$ in CCP4i to orient the models in the same space (results not shown). Binding to His15 was confirmed using both $F_{\mathrm{o}}-F_{\mathrm{c}}$ and anomalous difference electron-density maps (Fig. 2), with large peaks observed for the Pt ions. The occupancies observed for cisplatin and carboplatin binding to the $\mathrm{N}^{\delta}$ and $\mathrm{N}^{\varepsilon}$ atoms of His15 were in the range $32-82 \%$ for the EVAL15-processed data (Table 6). Each data set was also processed via MOSFLM and either $d^{*} T R E K$ (R-AXIS IV detector) or PROTEUM2 (Bruker detector); the occupancies for the $\mathrm{Pt}$ ions are also given in Table 6 along with the mean and standard deviations averaged across the results from these processing programs. The mean value range of $47-85 \%$ is higher than the results of Casini, Mastrobuoni et al. (2007), who reported $50 \%$ occupancy for cisplatin at the $\mathrm{N}^{\varepsilon}$ atom of His15 (PDB entry 2i6z) and $<15 \%$ occupancy for carboplatin binding to His15 (no coordinate file was deposited in the PDB for this case). This would be quite reasonable as the cocrystallization time that we have used allows a longer chemical reaction with the histidine, resulting in higher occupancy. Of course, the 'microenvironment' of the His15 side chain in the preformed crystal is not the same as that in solution. Comparing our cisplatin/DMSO structure with Paratone with 2i6z (Fig. 3), the $\mathrm{N}^{\delta}$ atom is shifted by $0.40 \AA$, which could facilitate binding of the second Pt ion in the cocrystallization method which is not seen in the soaking method. However, only a $2 \sigma$ confidence level is estimated from the coordinate errors and the Cruickshank DPI values $(0.40 \pm 0.18 \AA)$, meaning that this shift is not significant at a $3 \sigma$ level as a reason for the binding of the second $\mathrm{Pt}$ ion. The Pt-to-nitrogen distances in Figs. 2 and 7 are shown in Table 7, with the precisions of the bond distances shown in parentheses. The means and standard deviations of these bond lengths have also been calculated using the refined structures based on data from EVAL15, MOSFLM and either $d^{*} T R E K$ or PROTEUM2. There is a slight difference between the Pt-tonitrogen distances of $\sim 2.3-2.4 \AA$ in Table 7 and those of $2.1 \AA$ in Casini et al. (2007) and $2.1 \AA$ in Calderone et al. (2006), but the standard uncertainties evident in Table 7 are too large to confirm a real difference of $0.2-0.3 \AA$.

Owing to the difference that can be seen in Table 6 for the overall average $B$ factors from each of the four software programs, a selection of ten representative HEWL structures at $100 \mathrm{~K}$ from the PDB was made (Supplementary Table $\mathrm{S}^{\mathbf{1}}$ ). The mean and standard deviation of the overall average $B$ factors from these ten structures were $17.2 \pm 3.42 \AA^{2}$. To compare the four processing programs used here, the average $B$ factors were $d^{*}$ TREK, $33.65 \pm 4.12 \AA^{2}$; PROTEUM2, 19.16

\footnotetext{
${ }^{1}$ Supplementary material has been deposited in the IUCr electronic archive (Reference: MN5006). Services for accessing this material are described at the back of the journal.
} 
Table 6

Occupancies (shown as percentages) of cisplatin and carboplatin binding to the $\mathrm{N}^{\delta}$ and $\mathrm{N}^{\varepsilon}$ atoms of His 15 calculated from $S H E L X T L$ for all data sets processed via either $d^{*}$ TREK or PROTEUM2, MOSFLM and EVAL15.

The overall average $B$ factor for each structure is given for all three processing programs along with the mean and standard deviation for the occupancy values at each binding site between the different processing programs. The total occupancies for both binding sites and the $\sigma$ on this are also given (far right column).

\begin{tabular}{|c|c|c|c|c|c|c|c|c|c|c|c|c|}
\hline & \multicolumn{3}{|c|}{$d^{*} T R E K / P R O T E U M 2$} & \multicolumn{3}{|c|}{ MOSFLM } & \multicolumn{3}{|c|}{ EVAL15 } & \multicolumn{2}{|l|}{ Mean \pm s.d. } & \multirow[b]{2}{*}{ Total occupancy/o } \\
\hline & $\mathrm{N}^{\delta}$ & $\mathrm{N}^{\varepsilon}$ & $B$ factor $\left(\AA^{2}\right)$ & $\mathrm{N}^{\delta}$ & $\mathrm{N}^{\varepsilon}$ & $B$ factor $\left(\AA^{2}\right)$ & $\mathrm{N}^{\delta}$ & $\mathrm{N}^{\varepsilon}$ & $B$ factor $\left(\AA^{2}\right)$ & $\mathrm{N}^{\delta}$ & $\mathrm{N}^{\varepsilon}$ & \\
\hline $4 \mathrm{dd} 4$ & 67 & 52 & 23.6 & 66 & 51 & 21.5 & 76 & 52 & 14.7 & $69.6 \pm 5.51$ & $51.6 \pm 0.57$ & $1.21(0.06)$ \\
\hline 4dd7 & 67 & 54 & 15.8 & 64 & 52 & 13.7 & 66 & 54 & 13.6 & $65.6 \pm 1.52$ & $53.3 \pm 1.15$ & $1.18(0.03)$ \\
\hline $4 \mathrm{dd} 9$ & 65 & 50 & 29.9 & 74 & 47 & 23.1 & 68 & 47 & 18.6 & $69.0 \pm 4.58$ & $48.0 \pm 1.73$ & $1.17(0.06)$ \\
\hline $4 \mathrm{ddb}$ & $88 \dagger$ & $60 \dagger$ & $42.1 \dagger$ & $\ddagger$ & $\$$ & $\$$ & 82 & 43 & 17.8 & $85.0 \pm 4.24$ & $51.5 \pm 12.02$ & $1.36(0.16)$ \\
\hline $4 \mathrm{ddc} \S$ & 65 & 63 & 16.2 & 50 & 86 & 30.2 & 32,40 & 55,43 & 16.2 & $46.7 \pm 14.22$ & $61.7 \pm 18.13$ & $1.08(0.32)$ \\
\hline
\end{tabular}

$\dagger$ During processing in $d^{*} T R E K$ only 81 images were integrated. $R_{\text {merge }}$ values greater than 0.25 per image were rejected. $E V A L 15$ processing did not have a problem with these images,

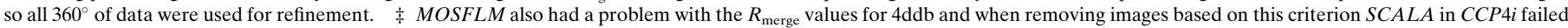

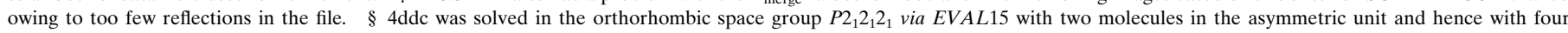
molecules of cisplatin bound. However, the tetragonal space group $P 4_{3} 2_{1} 2$ was given by MOSFLM and PROTEUM2.

\section{Table 7}

The platinum-to-histidine imidazole $\mathrm{N}$ distances $(\AA)$ from refinement using the data sets processed via EVAL15, MOSFLM and either $d^{*} T R E K$ or PROTEUM2 for the R-AXIS IV or Bruker data sets, respectively.

The precisions of these distances are indicated in parentheses based on the Cruickshank DPI (Cruickshank, 1999) coordinate errors for each pair of atoms (Pt and N) from each model refinement. The means and standard deviations between the software processing programs for the same data set are also supplied.

\begin{tabular}{|c|c|c|c|c|c|c|c|c|}
\hline \multicolumn{3}{|c|}{ EVAL15 } & \multicolumn{2}{|l|}{ MOSFLM } & \multicolumn{2}{|c|}{$d^{*}$ TREK/PROTEUM2 } & \multicolumn{2}{|l|}{ Mean \pm s.d. } \\
\hline & $\mathrm{N}^{\delta}$ & $\mathrm{N}^{\varepsilon}$ & $\overline{\mathrm{N}^{\delta}}$ & $\mathbf{N}^{\varepsilon}$ & $\mathrm{N}^{\delta}$ & $\mathrm{N}^{\varepsilon}$ & $\overline{\mathrm{N}^{\delta}}$ & $\mathrm{N}^{\varepsilon}$ \\
\hline $4 \mathrm{dd} 4$ & $2.37(0.24)$ & $2.29(0.23)$ & $2.40(0.19)$ & $2.35(0.18)$ & $2.41(0.22)$ & $2.30(0.21)$ & $2.39(0.02)$ & $2.31(0.03)$ \\
\hline $4 \mathrm{dd} 9$ & $2.33(0.22)$ & $2.33(0.21)$ & $2.35(0.49)$ & $2.38(0.49)$ & $2.33(0.16)$ & $2.34(0.16)$ & $2.33(0.01)$ & $2.35(0.02)$ \\
\hline $4 \mathrm{ddb}$ & $2.54(1.33)$ & $2.38(1.50)$ & $\dagger$ & $\dagger$ & $2.52(0.78)$ & $2.36(0.85)$ & $2.53(0.01)$ & $2.37(0.01)$ \\
\hline 4ddc $\_A$ & $2.67(0.48)$ & $2.26(0.40)$ & $2.10(1.06)$ & $2.45(1.12)$ & $2.70(0.97)$ & $2.23(0.87)$ & $2.49(0.34)$ & $2.31(0.12)$ \\
\hline
\end{tabular}

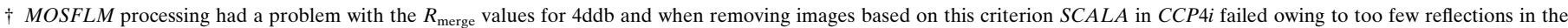
file.

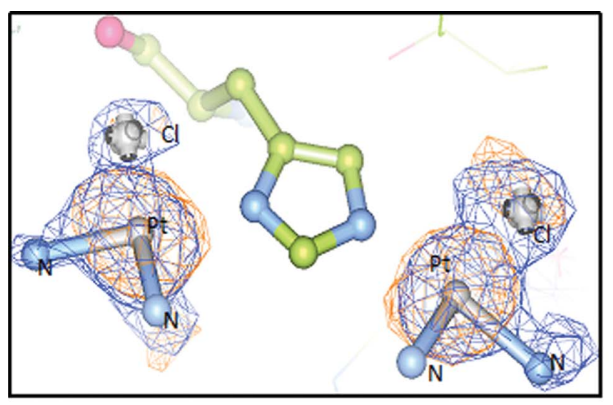

$(a)$

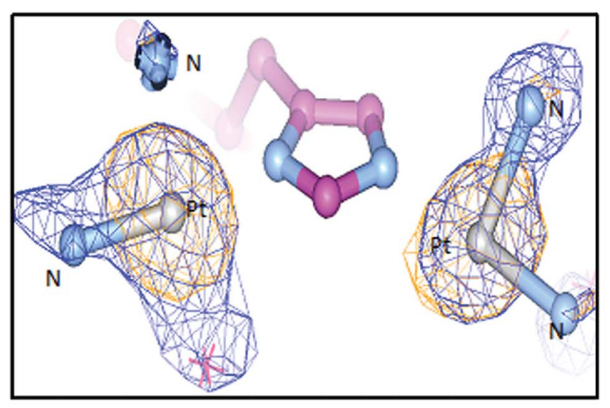

(d)

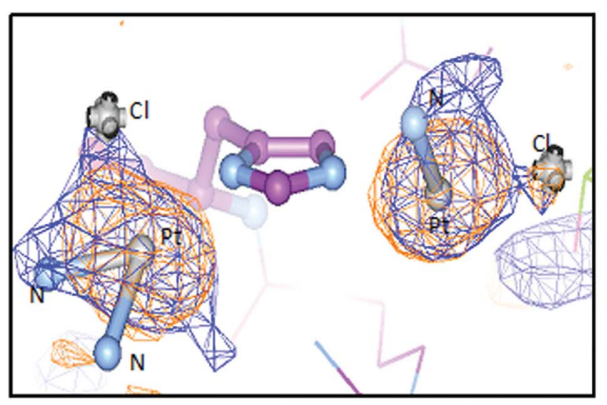

(b)

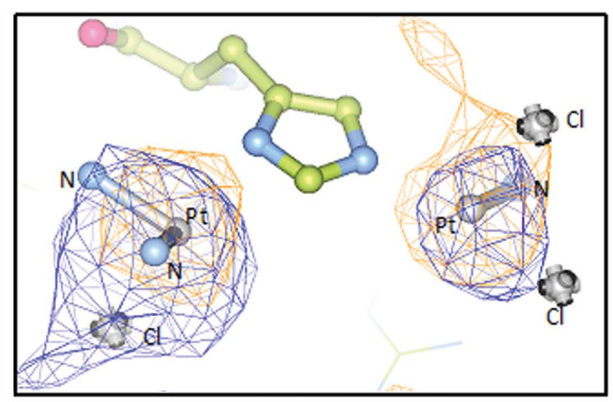

(e)

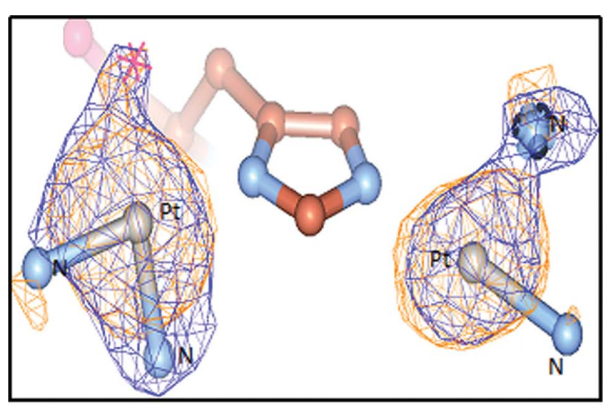

$(c)$

Figure 2

$F_{\mathrm{o}}-F_{\mathrm{c}}$ and anomalous difference density maps around His15 for the cases of cisplatin and carboplatin with DMSO. Anomalous difference density (orange) is shown at $3 \sigma$ in $(a)-(d)$ and $2.5 \sigma$ in $(e)$ and $F_{\mathrm{o}}-F_{\mathrm{c}}$ density (blue) is shown at $3 \sigma .(a, b)$ Two molecules of cisplatin are bound to His15 at $\mathrm{pH} 4.7$ with glycerol and Paratone used as the cryoprotectant, respectively. $(c, d)$ Two molecules of carboplatin are bound to His15 at $\mathrm{pH} 4.7$ with glycerol and Paratone used as the cryoprotectant, respectively. (e) Two molecules of cisplatin are bound to His15 at $\mathrm{pH}$ 6.5. The $\mathrm{Pt}, \mathrm{N}$ and $\mathrm{Cl}$ atoms of cisplatin and carboplatin are labelled. The Pt$\mathrm{N}^{\delta}$ and $\mathrm{Pt}-\mathrm{N}^{\varepsilon}$ distances are given in Table 7. 
$\pm 3.58 \AA^{2} ;$ MOSFLM, $24.1 \pm 10.2 \AA^{2} ;$ EVAL15, 18.2 $\pm 4.7 \AA^{2}$. Obviously, these values may include contributions from crystallization and freezing in addition to the intrinsic flexibility of lysozyme, but they are helpfully indicative.

3.1.2. DMSO-binding details. A DMSO molecule was bound at lysozyme saccharide-binding site $C$ of the active site of the enzyme in all crystals tested (Fig. 4); it was bound by Trp63 and Trp108 and confirmed by the presence of anomalous difference density for the $\mathrm{S}$ atom. This binding site for DMSO coincides with the deposited coordinates (PDB entry 2i6z) of Casini, Mastrobuoni et al. (2007).

\subsection{Absence of binding of cisplatin and carboplatin in aqueous media}

As DMSO was bound in the active site of HEWL, mimicking sugar binding, aqueous conditions were used to remove the DMSO inhibitory effect. The aim was to determine whether carboplatin, with its similar shape to a sugar molecule, might mimic sugar binding in the active site. However, no cisplatin or carboplatin binding was observed at the enzyme active site; moreover, surprisingly, no binding was observed at His15 at these crystallization timescales of $4-8$ days. There was appropriately shaped $F_{\mathrm{o}}-F_{\mathrm{c}}$ electron density at the enzyme active site for the two cryoprotectants used: glycerol (Figs. $5 a$ and $5 c$ ) and Paratone (Figs. $5 b$ and $5 d$ ). As a further check, we noted the absence of anomalous difference density (i.e. that might have arisen from a Pt atom). Therefore, in the case with DMSO the DMSO must somehow facilitate cisplatin and carboplatin binding to the $\mathrm{N}$ atoms of His15. Using $L S Q K A B$ in $C C P 4 i$, it was noted that the protein conformation is basically the same in the "with DMSO conditions' and in the 'without DMSO conditions'; thus, the addition of DMSO does not cause any changes in protein conformation (results not shown).

\subsection{Cocrystallization of HEWL with NAG and cisplatin}

The cocrystallization of HEWL with its natural substrate NAG and cisplatin was carried out to assess whether cisplatin binding caused any effect upon NAG binding in the active site. HEWL was first cocrystallized with NAG only to confirm its binding in the enzyme active site. A 150-fold molar excess was used, as monosaccharide NAG has low-affinity binding compared with trisaccharide NAG (Blake et al., 1967).
NAG binding was observed at enzyme active site $D$ with an occupancy of $77 \%$ as calculated in SHELXTL (Fig. 6). Monosaccharide NAG usually has a greater affinity for site $C$ rather than site $D$ (Perkins et al., 1981).

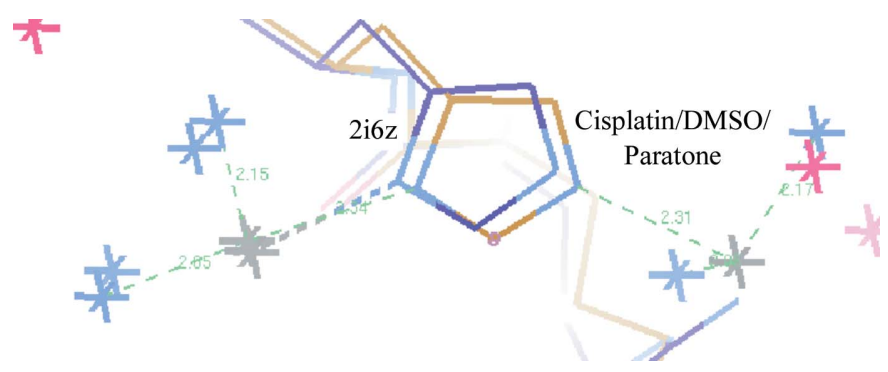

Figure 3

Overlay of His15 from 2i6z (purple) and our cisplatin/DMSO/Paratone structure (orange) at $\mathrm{pH}$ 4.7. The left-hand binding site $\left(\mathrm{N}^{\delta}\right)$ has the $\mathrm{Pt}$ ion in the same place and the right-hand binding site has the $\mathrm{N}^{\varepsilon}$ atom shifted by $0.40 \AA$.
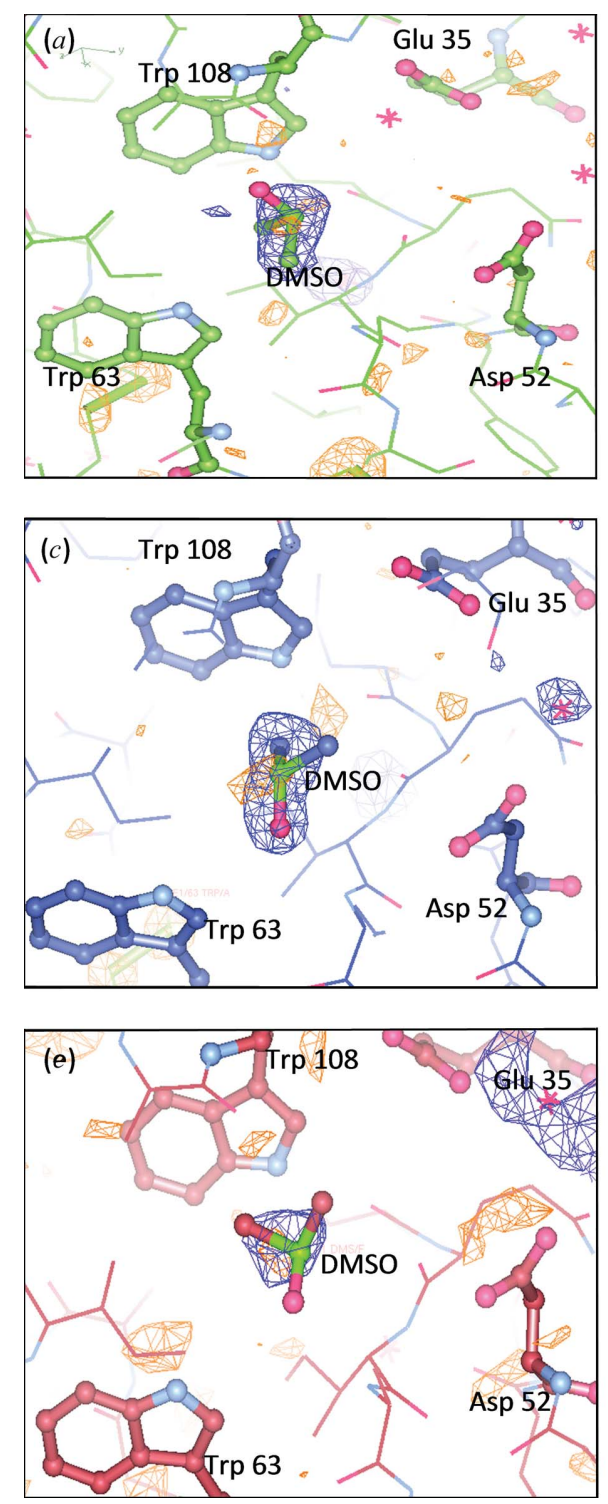
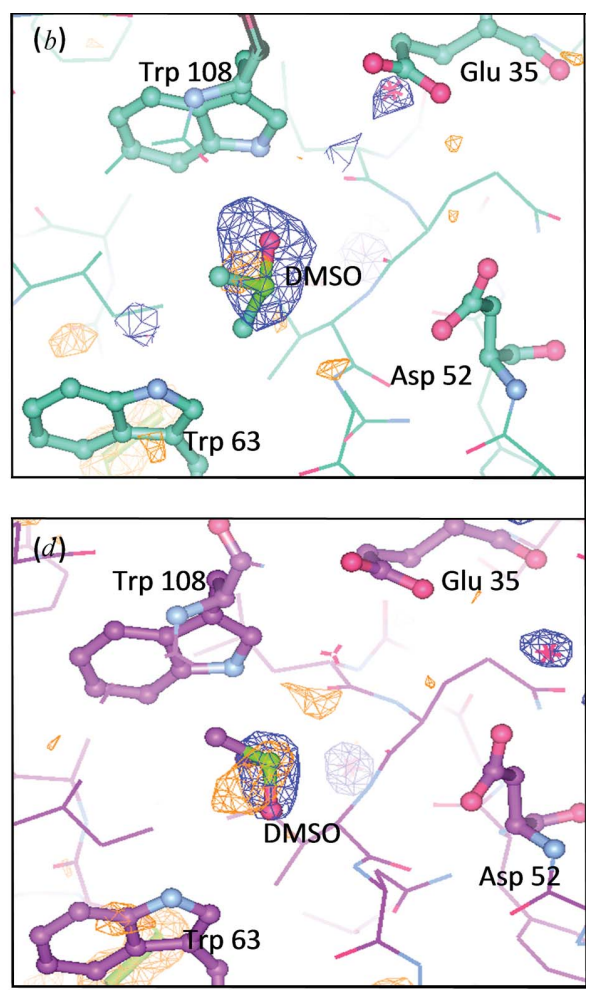

Figure 4

DMSO binding in active site $C$ of HEWL. $(a, b)$ Cocrystallization of cisplatin with glycerol $(a)$ and Paratone $(b)$ as the cryoprotectant at $\mathrm{pH}$ 4.7. $(c, d)$ Cocrystallization of carboplatin with glycerol $(c)$ and Paratone $(d)$ as the cryoprotectant at $\mathrm{pH}$ 4.7. (e) Cisplatin cocrystallization at pH 6.5 with Paratone as the cryoprotectant. The two catalytic residues Asp52 and Glu35 in site $D$ and Trp63 and Trp108 which line active site $C$ are shown. The $F_{o}-F_{\mathrm{c}}$ density maps (blue) at $3 \sigma$ and anomalous difference density maps (orange) at $2.5 \sigma$ are also shown. DMSO binding is confirmed by the presence of an anomalous difference density map peak, albeit at $2.5 \sigma$. 
A separate cocrystallization experiment was conducted using HEWL with NAG together with the addition of $7.5 \%$
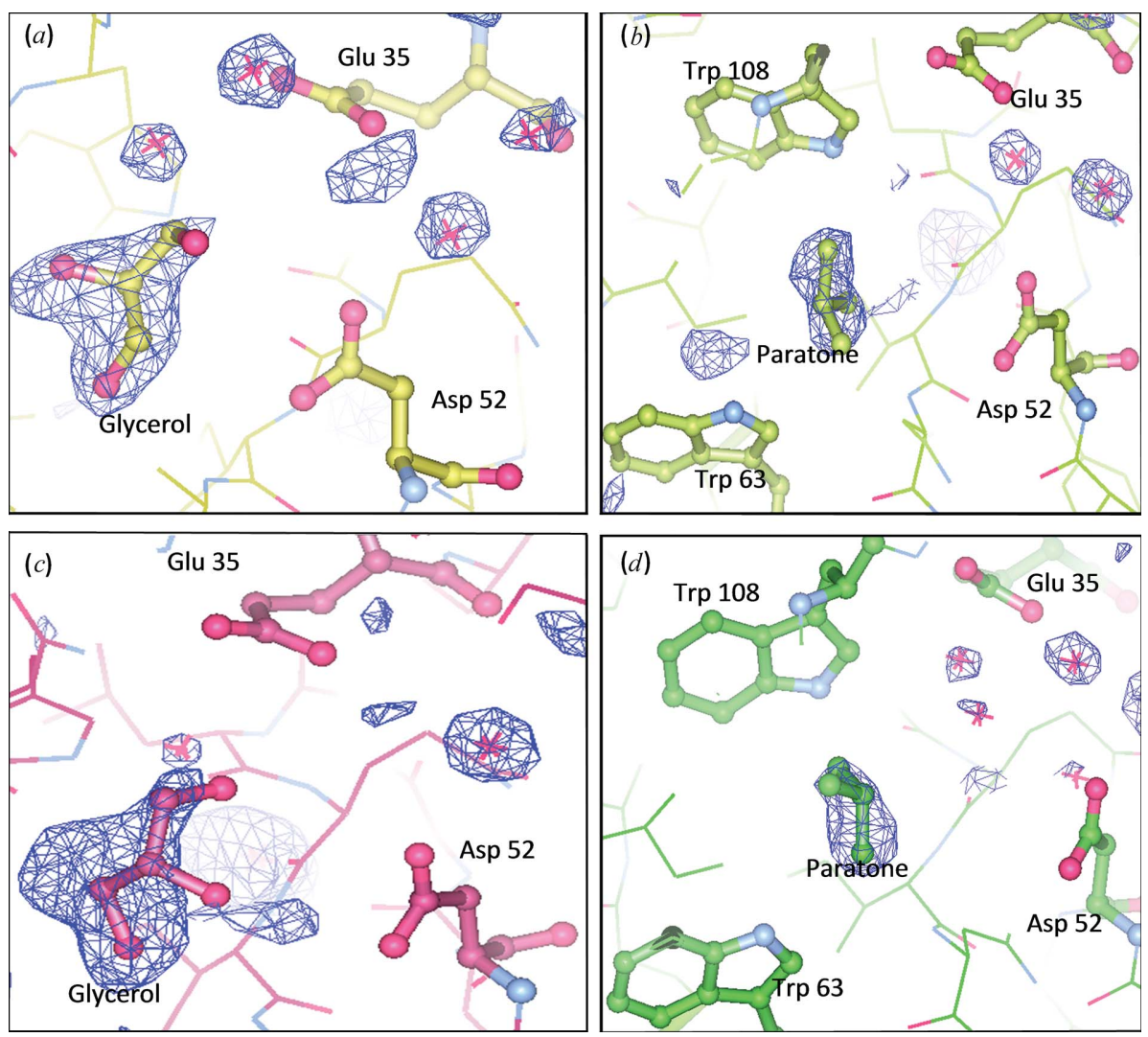

Figure 5

The active site of HEWL, showing the catalytic residues Asp52 and Glu35. $F_{\mathrm{o}}-F_{\mathrm{c}}$ density maps (blue) are shown at $2.3 \sigma$. Glycerol is observed bound in active site $D$ when used as the cryoprotectant for both the cisplatin $(a)$ and carboplatin $(c)$ cocrystallization cases. When Paratone was used as the cryoprotectant it was found bound in active site $C$, as observed for both the cisplatin (b) and carboplatin (d) cocrystallization cases. Paratone and its monomer (isobutylene) are insoluble, meaning that binding to HEWL is unlikely; however, from the shape of the $F_{o}-F_{\mathrm{c}}$ density, and as Paratone conditions were used, binding of Paratone is a possible explanation, with the two Trp residues (Trp63 and Trp108) in site $C$ providing a hydrophobic environment for binding to take place.

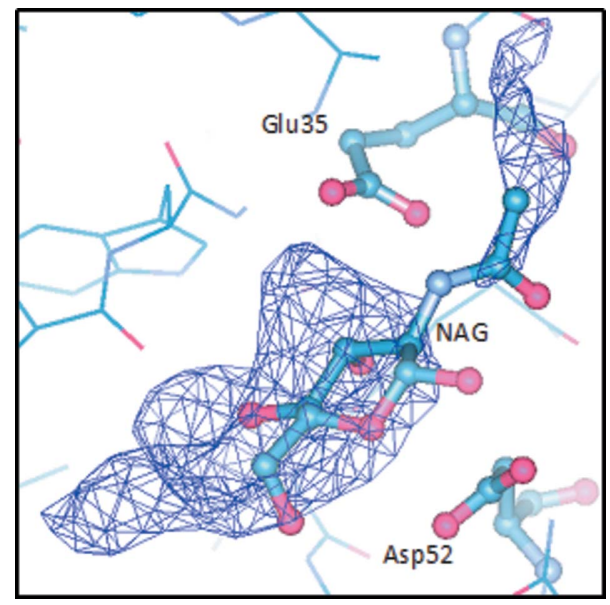

Figure 6

Monosaccharide NAG binding in site $D$ of the active site of HEWL. The $F_{o}-F_{\mathrm{c}}$ density map (blue) is shown at a $2.5 \sigma$ cutoff.
DMSO and a threefold molar excess of cisplatin. HEWL crystallized in the orthorhombic space group $P 2_{1} 2_{1} 2_{1}$, with two molecules of HEWL in the asymmetric unit. Two molecules of cisplatin were again observed bound to either side of His 15 in chain $A$, with occupancies of 32 and $55 \%$ for the $\mathrm{N}^{\delta}$ and $\mathrm{N}^{\varepsilon}$ binding sites, respectively, and in chain $B$, with occupancies of 40 and $43 \%$ for the $\mathrm{N}^{\delta}$ and $\mathrm{N}^{\varepsilon}$ binding sites, respectively (one of the binding sites is shown in Fig. 7). Based on the above results, we may expect either NAG or DMSO, or both, to be bound in the enzyme active site. In this case, the binding of a DMSO molecule is observed (Fig. 8) based on anomalous difference density of $2.5 \sigma$ in the active site. [In Fig. 8 DMSO is bound in site $D$. It is in a different place than in Fig. 4 (site $C$ ). However, we are not sure why this is.]

\section{Discussion}

\subsection{The initial experimental concepts for these studies}

Our initial impetus and interest in embarking on this study arose from the idea that carboplatin could bind to the active site of HEWL, thus mimicking sugar binding ( $\mathrm{Li}, 2006)$, and if so it would also be an interesting toxicity side effect of this important drug treatment used in veterinary practice. Binding to the active site could lead to the use of carboplatin as a cofactor in the cocrystallization of sugar-binding proteins and structure determination using isomorphous replacement owing to the anomalous scattering power of the Pt ion. Obviously, these ideas also connected with the use of cisplatin and carboplatin in medicine and veterinary practice, as carboplatin and cisplatin are similarly acting anticancer chemotherapeutics.

We found that Casini, Mastrobuoni et al. (2007) had published an X-ray crystallographic study of HEWL crystals soaked with cisplatin (PDB entry 2i6z) and had also investigated carboplatin via the crystal-soaking method, whilst first using MS to confirm the binding of either platinum complex to the protein. The results obtained from their structural analysis confirmed the binding of cisplatin to His 15 of HEWL with an occupancy of around $50 \%$ at one $\mathrm{N}$ atom of the imidazole ring. No crystal structure was reported for the HEWL carboplatin crystal-soaking experiment, but ICP-OES data showed very weak binding $(<15 \%)$. However, MS studies indicated a clear mass change upon the binding of carboplatin and indicated a doubly-platinated HEWL structure for both the cisplatin and 
the carboplatin cases. PDB entry $2 \mathrm{i} 6 \mathrm{z}$ also showed a DMSO molecule bound in the active site, mimicking sugar binding.

We have been able to build on the important findings of Casini, Mastrobuoni et al. (2007) in the results presented in this article. The method of cocrystallization of HEWL with cisplatin or carboplatin was used in order to avoid any possible crystal-lattice hindrance that may have affected the carboplatin crystal soaking. The use of DMSO media was carried out for a direct comparison and the use of aqueous conditions was added in a further set of experiments to avoid the possible chemical complications that may have occurred with DMSO in confirming whether carboplatin (or cisplatin) might bind in the enzyme active site. A potential further chemical complication is the choice of cryoprotectant, as it is well known that glycerol has specific binding sites in proteins, including mimicking sugars, which is also of interest here. The cryoprotectant used by Casini, Mastrobuoni et al. (2007) was not specified. In our studies both glycerol and Paratone were used, and finally also silicone oil in the studies of lysozyme with NAG. We included the cocrystallization of HEWL with its natural substrate NAG in our range of chemical conditions to be varied in order to confirm binding in the active site. These

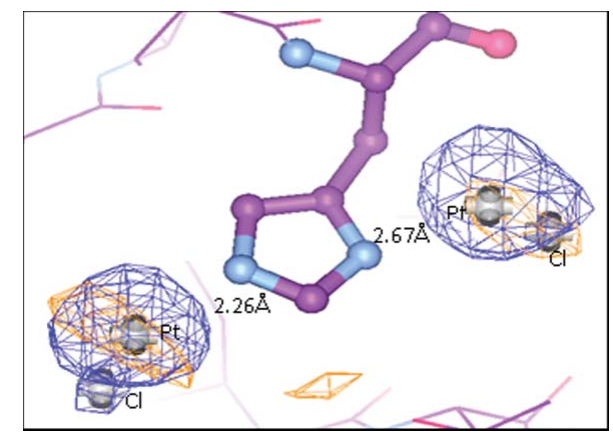

Figure 7

Cisplatin binding to the $\mathrm{N}^{\delta}$ and $\mathrm{N}^{\varepsilon}$ atoms of His 15 for HEWL with NAG, cisplatin and DMSO. $F_{\mathrm{o}}-F_{\mathrm{c}}$ electron density (blue) at $3 \sigma$ and anomalous difference electron density (orange) at $3 \sigma$ are shown for one of the independent lysozyme molecules. The $\mathrm{Pt}-\mathrm{N}^{\delta}(2.67 \AA)$ and $\mathrm{Pt}-\mathrm{N}^{\varepsilon}(2.26 \AA)$ distances are shown and the standard uncertainties are given in Table 7.

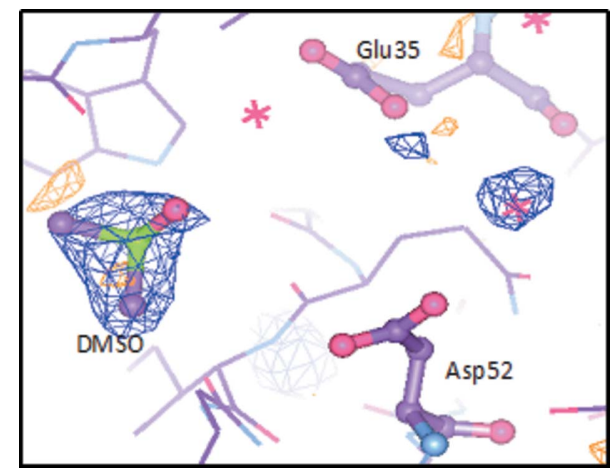

Figure 8

One molecule of DMSO modelled into active site $D$ of HEWL. $F_{\mathrm{o}}-F_{\mathrm{c}}$ density (blue) is shown at $2.5 \sigma$ and anomalous difference density (orange) is shown at 2.5o. The catalytic residues Asp52 and Glu35 are also shown. data were used as a reference for comparison with HEWL cocrystallized with NAG and cisplatin in DMSO conditions to confirm whether cisplatin binding caused any effect on NAG binding to the active site.

\subsection{Chemical rationalization of cisplatin or carboplatin binding to both histidine $\mathbf{N}$ atoms}

In the DMSO crystallization conditions, we found that two molecules of cisplatin or carboplatin were coordinated to one histidine moiety: His15. The two metal centres are linked to the $\mathrm{N}^{\delta}$ and $\mathrm{N}^{\varepsilon}$ atoms of the imidazole ring (Fig. 2) at $\mathrm{pH}$ 4.7. The cisplatin study was repeated at $\mathrm{pH} 6.5$ using cocrystallization. This structural unit (one histidine and two platinum centres) means that in the imidazole of this histidine the usual $\mathrm{N}$-hydrogen of such a residue is absent and that both $\mathrm{N}$ atoms are $s p^{2}$-hybridized with nitrogen lone pairs in the plane of the imidazole ring: effectively, it is an imidazolyl anion. (The 'imidazolyl anion' is the same as 'imidazolate'; see below.) This then provides two $\mathrm{N}$ atoms at which a metal centre can bind. The loss of this $\mathrm{H}$ atom (as a proton) is made possible by the crystallization conditions used, which contained chloride and acetate ions that could remove the N-hydrogen. The removal of the N-hydrogen would be facilitated by coordination of the imine $\mathrm{N}$ atom of the histidine to platinum. The situation is summarized in Fig. 9. This is a plausible explanation for the high occupancies seen for the binding of both carboplatin and cisplatin to either $\mathrm{N}$ atom of His 15 at both $\mathrm{pH} 4.7$ and 6.5 (Table 6). The notion of His15 conformational flipping in the structure as a static disorder effect, meaning that only one cisplatin/carboplatin molecule has chemically bound, can be ruled out owing to the fact that a $\mathrm{C}$ atom would now have to be coordinated to the $\mathrm{Pt}$ ion, which it obviously is not.

In solution at a $\mathrm{pH}$ similar to the $\mathrm{p} K_{\mathrm{a}}(6.0-6.3)$, about equal amounts of the ionic protonated state and the deprotonated state of histidine occur, the latter possibly in two tautomeric forms $a$ and $b$ (Farr-Jones et al., 1993; Fig. 10). Thus, a further possible explanation for the two observed $\mathrm{Pt}$ sites is provided by these two tautomeric forms, allowing either $\mathrm{N}^{\delta}$ or $\mathrm{N}^{\varepsilon}$ to participate in the interaction with $\mathrm{Pt}$.

The imidazolate ion mentioned above is described in Rhodes (2005) (form $D$; Fig. 11).

A positively charged platinum moiety would thus be a favourable situation for the histidine to have a charge of -1 , thus stabilizing the imidazolate anion.

\subsection{Estimations of platinum occupancies and their associated standard uncertainties}

The occupancy estimates calculated using SHELXTL at this diffraction resolution are without standard uncertainties. The uncertainty values for these occupancies are generally regarded as probably being around $\pm 5 \%$. Table 6 gives the mean values, the summed occupancies and the standard uncertainties for the $\mathrm{N}^{\delta}$ and $\mathrm{N}^{\varepsilon}$ binding sites for each crystal grown in DMSO medium based on reprocessing of the same data set using three different programs $\left(d^{*} T R E K\right.$ or PROTEUM2, MOSFLM and EVAL15). The standard 


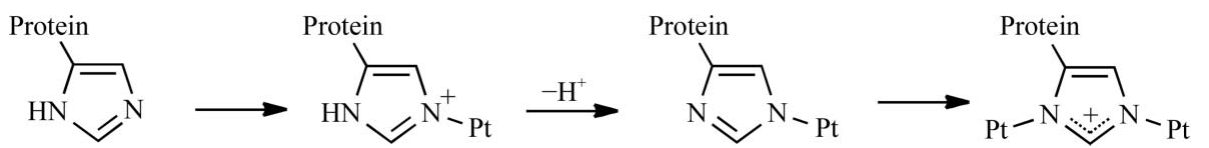

Figure 9

Removal of the the N-hydrogen from histidine.

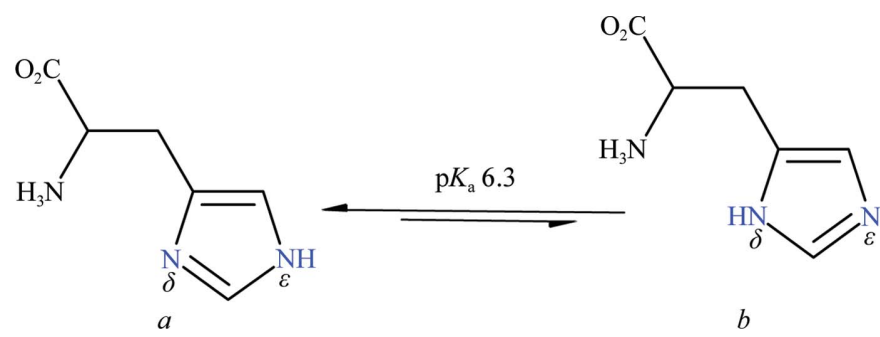

Figure 10

Tautomeric forms of deprotonated histidine.

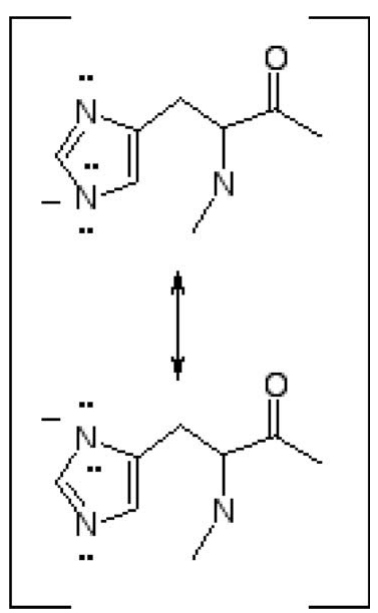

Figure 11

The imidazolate ion (see Rhodes, 2005).

uncertainties in the Pt-atom occupancies derived from repeat data processing with the different diffraction data-processing software include random errors but not systematic errors. The latter are not expected to be large since the bulk of the protein atoms with full occupancy compared against the absolute atomic scattering factors in the SHELXTL refinement create the required absolute scale. As the summed occupancies are all larger than 1.0 (Table 6) it seems that the imidazolyl-anion hypothesis mentioned above is most likely, rather than a chemical resonance effect. It is only 4ddc which gives standard uncertainties greater than \pm 5 and this is a consequence of the fact that the MOSFLM and PROTEUM2 processing did not recognize the orthorhombic symmetry; all other standard uncertainties were $\sim \pm 5 \%$. The occupancy at the $\mathrm{N}^{\varepsilon}$ atom of $4 \mathrm{ddb}$ also has a larger standard uncertainty, but only two values were used as this data set was not processed via MOSFLM owing to problems in rejecting images based on large $R_{\text {merge }}$ values. $4 \mathrm{dd} 4,4 \mathrm{dd} 9$ and $4 \mathrm{ddc}$ also show a larger change in the overall average $B$ factor across the three different processing programs; however, this software effect does not cause an effect on the estimation of the occupancy at each binding site in these crystals. The average $B$ factors for PROTEUM2 $\left(19.16 \pm 3.38 \AA^{2}\right)$ and $E V A L 15(18.2 \pm$ $4.7 \AA^{2}$ ) are comparable, whereas those for MOSFLM (24.1 $\left.\pm 10.2 \AA^{2}\right)$ and $d^{*}$ TREK $\left(33.65 \pm 4.12 \AA^{2}\right)$ are larger for our 11 diffraction data sets. Comparing the average $B$ factors between the processing programs shows that there is indeed variation. The processing details from the different programs will be summarized in a second paper (Tanley et al., 2012).

\subsection{DMSO, glycerol and Paratone binding details}

Besides the cisplatin and carboplatin binding behaviour, the DMSO binding is of interest. A DMSO molecule was indeed observed bound in site $C$ of the enzyme active site (Fig. 4), thus acting as a competitive inhibitor of HEWL. A second DMSO molecule was coordinated by Trp123, and these findings corroborate those of Jóhannesson et al. (1997). In the presence of NAG, DMSO still seems to bind at the enzyme active site, acting in a competitive manner (Fig. 8).

Aqueous crystallization conditions were used to remove the inhibitory effect seen with DMSO at the enzyme active site, but also to evaluate whether DMSO had an impact on binding of cisplatin or carboplatin to His15. A complication at the enzyme active site is that in both the glycerol and Paratone cases a molecule of cryoprotectant binds to the active site (Fig. 5) in the absence of DMSO. Paratone is a polymeric hydrocarbon, $\left(\mathrm{C}_{4} \mathrm{H}_{8}\right)_{17}$, but only the monomeric form $\left(\mathrm{C}_{4} \mathrm{H}_{8}\right)$ was observed to bind in the active site. The $F_{\mathrm{o}}-F_{\mathrm{c}}$ density maps obtained with glycerol contained further unmodelled density corresponding to additional glycerol molecules bound to other sites on HEWL. In contrast, the $F_{\mathrm{o}}-F_{\mathrm{c}}$ map obtained with Paratone contained less unmodelled density related to bound Paratone molecules, making the refinement steps less complicated; as a consequence of these findings, it would be advantageous to use Paratone over glycerol. However, silicone oil would also be advantageous to use as it was not observed to bind to HEWL when used as the cryoprotectant in the NAG cases.

Using aqueous conditions, within our studied timescales of up to eight days for binding, it was found that neither cisplatin nor carboplatin bound to His15. Therefore, addition of DMSO to the crystallization conditions increased the affinity of cisplatin and carboplatin to bind to His 15 of HEWL. DMSO is a super-solvent that is used for targeted drug delivery as it is perceived to have no effect upon drug binding (Dearman et al., 1998; Abedini et al., 2004; Axanova et al., 2005; Peaston \& Maddison, 2006; Huang et al., 2007). However, our results led to the conclusion that addition of DMSO causes binding of cisplatin and carboplatin to occur at a His residue. This therefore must be a cause for concern as it may cause an increase in the toxic effects of both cisplatin and carboplatin owing to their binding to proteins that they would not normally bind to in aqueous conditions. Fischer et al. (2008) indeed proposed that cisplatin should not be used in 
conjunction with DMSO owing to the rapid reaction that occurs between the two and that results in the formation of a cisplatin-DMSO adduct which loses cytotoxicity towards tumour cells and has increased toxic side effects. In our crystallization conditions both cisplatin and carboplatin did not fully dissolve in $7.5 \%$ DMSO immediately, but after $12 \mathrm{~h}$ all of the cisplatin and carboplatin had dissolved; this was also observed in the aqueous conditions used. The cisplatinDMSO adduct was not observed in any of the crystal structures presented here; based on our findings, direct coordination of DMSO to $\mathrm{Pt}$ might alter the compound reactivity in solution, not only with respect to HEWL binding.

\subsection{Comparison with $2 \mathrm{i} 6 \mathrm{z}$}

Compared with Casini, Mastrobuoni et al. (2007), who observed one cisplatin binding to His15 (PDB entry 2i6z), we find that two molecules of cisplatin and carboplatin bind to His15. This may simply result from the longer time afforded to the chemical reaction during the crystallization process. Of course, as remarked above, the 'microenvironment' of the His15 side chain in the preformed crystal is not the same as that in solution. As an alternative explanation, it is not obvious what chemical condition is different. Indeed, the MS study of Casini, Mastrobuoni et al. (2007) indicated double platination. It is also not obvious why cocrystallization might allow binding at each $\mathrm{N}$ atom of the platinum complex, as the solvent channel in the crystal seems to give open access to His15 in the soaking case (Casini, Mastrobuoni et al., 2007). We nevertheless overlayed our cisplatin-lysozyme crystal structure with $2 \mathrm{i} 6 \mathrm{z}$ and observed a His 15 side-chain shift. We can evaluate whether this is a significant shift as follows. The His residue is shifted by $0.40 \AA$ for our coordinates versus PDB entry 2i6z (Fig. 3). The coordinate error of each atom is calculated using (1), via which the Cruickshank DPI values (Cruickshank, 1999; Blow, 2002) can confirm whether the coordinate shift is significant,

$$
\text { coordinate error of atom }=\mathrm{DPI} *\left(B_{\text {atom }} / B_{\text {average }}\right)^{1 / 2} .
$$

We use the coordinate error rather than the positional error of the atom as the shift of the atom is in one direction only. (The positional error takes into account the shift in three directions, with that error being $3^{1 / 2}$ times larger than the coordinate error; Cruickshank, 1999).

The standard deviation of the calculated shift is determined using the coordinate error of the $\mathrm{N}$ atoms in both structures 1 and 2 ,

$$
\begin{aligned}
\text { standard deviation }= & {\left[(\text { coordinate error } 1)^{2}\right.} \\
& \left.+(\text { coordinate error } 2)^{2}\right]^{1 / 2} .
\end{aligned}
$$

The value and standard uncertainty for the shift of the $\mathrm{N}$ atoms are $0.40 \pm 0.18 \AA$. This gives a value of only just over $2 \sigma$, or a $95.4 \%$ level of confidence, rather than the usually desirable $3 \sigma$ or $99.7 \%$ level of confidence that this coordinate shift is significant.

\subsection{NAG binding}

NAG is the natural substrate of HEWL and usually binds in site $C$ of the active site (Perkins et al., 1981). Our crystal structure of HEWL with NAG has NAG bound in the less favourable site $D$ (Fig. 6). Upon cocrystallizing HEWL, NAG and cisplatin in DMSO medium, the observed $F_{\mathrm{o}}-F_{\mathrm{c}}$ density in the active site covers site $D$ (Fig. 8). However, this density is consistent with one molecule of DMSO binding, which is confirmed by the presence of anomalous difference electron density at $2.5 \sigma$, meaning that DMSO competes with NAG to bind in the active site.

\subsection{Comparison with other proteins binding cisplatin and implications for drug toxicity}

Only a handful of other proteins have been studied for their affinity to bind cisplatin, including copper transporter (Arnesano \& Natile, 2008; Crider et al., 2010), superoxide dismutase (Calderone et al., 2006; Casini et al., 2008), cytochrome c (Casini et al., 2006; Casini, Gabbiani et al., 2007), human albumin (Ivanov et al., 1998), ubiquitin (Hartinger et al., 2006), human copper chaperone (Boal \& Rosenzweig, 2009) and glutathione (Zimmermann \& Burda, 2010). These studies mostly used MS to confirm the binding of cisplatin to specific Met/Cys or His residues, with only the X-ray crystal structures of cisplatin bound to HEWL (Casini, Mastrobuoni et al., 2007), to a copper chaperone (Boal \& Rosenzweig, 2009) and to superoxide dismutase being available (Calderone et al., 2006; Casini et al., 2008). The free His residue available in HEWL is not involved in the catalytic mechanism; hence, cocrystallizing cisplatin or carboplatin with proteins (e.g. chymotrypsin, trypsin) whose catalytic site requires a His residue would be of benefit to determine whether catalysis is inhibited upon binding of these platinum compounds, which could be important in further assessment of the toxic effects of these drugs. Using cocrystallization techniques with the addition of DMSO could pave the way for increased analysis of protein-platinum anticancer drug interactions. These will lead to a better understanding of the pharmacokinetics, biodistribution, resistance processes and toxicity of these metallodrugs (Calderone et al., 2006; Casini et al., 2006; Casini, Mastrobuoni et al., 2007). However, crystallography can only provide data for a nonphysiological environment, in which the presence of high-salt buffer concentrations, as well as a high concentration of Pt drugs, are not realistic. Therefore, crystallographic data should be handled with care and always integrated with other techniques, i.e. mass spectrometry.

\section{Conclusions}

Both cisplatin and carboplatin do not bind to HEWL in aqueous media, within our studied timescales of up to eight days for binding, but do upon addition of DMSO. The DMSO causes two molecules of either cisplatin or carboplatin to bind to both imidazole $\mathrm{N}$ atoms of His15, the only His residue in HEWL. To confirm the relative identities of the atoms in the binding moieties, anomalous scattering maps were calculated 
and were cross-checked with $F_{\mathrm{o}}-F_{\mathrm{c}}$ OMIT maps to prove where the binding of the $\mathrm{Pt}$ atoms had occurred. The use of EVAL15 for processing all of the diffraction data sets provided a consistent platform for our large ensemble of data sets for the various protein and platinum-compound model refinements with REFMAC5 and then SHELXTL. Platinumoccupancy $\sigma$ values were finally calculated using the results from three different diffraction data-processing programs.

The implications of these results are important as DMSO is a super-solvent that is widely used for the delivery of these and other drugs. Since our results show that addition of DMSO accentuates the binding of platinum anticancer drugs to HEWL, this effect must be allowed for in toxicity assessments of these drugs. Further studies involving proteins with histidine in the active site and an assessment of cisplatin or carboplatin binding will lead to the potential side effects of these important anticancer agents being further understood.

JRH is grateful to the University of Manchester for general support, to the ESPRC for a PhD studentship to SWMT, to the School of Chemistry for crystallization and computing facilities and to the Faculty of Life Sciences for X-ray diffraction facilities (the Rigaku system has recently relocated to the Manchester Interdisciplinary Biocentre, but was previously at the Michael Smith Building Macromolecular Facility instigated by colleagues Dr Jordi Bella and Dr Lydia Tabernero, who are also thanked). Thanks also go to Professor Peter Halling, Dr Michele Cianci, Professor John Joule and Dr Alfons Haedener for discussions.

\section{References}

Abedini, M. R., Qiu, Q., Yan, X. \& Tsang, B. K. (2004). Oncogene, 23, 6997-7004.

Arnesano, F. \& Natile, G. (2008). Pure Appl. Chem. 80, 2715-2725.

Axanova, L., Morré, D. J. \& Morré, D. M. (2005). Cancer Lett. 225, 35-40.

Baliga, R., Zhang, Z., Baliga, M., Ueda, N. \& Shah, S. V. (1998). Kidney Int. 53, 394-401.

Benedetti, M., Malina, J., Kasparkova, J., Brabec, V. \& Natile, G. (2002). Environ. Health Perspect. 110, Suppl. 5, 779-782.

Blake, C. C. F., Johnson, L. N., Mair, G., North, C. T., Phillips, D. C. \& Sarma, V. R. (1967). Proc. R. Soc. B Biol. Sci. 167, 378-388.

Blow, D. M. (2002). Acta Cryst. D58, 792-797.

Blundell, T. L. \& Johnson, L. N. (1976). Protein Crystallography, pp. 66-77. New York: Academic Press.

Boal, A. K. \& Rosenzweig, A. K. (2009). J. Am. Chem. Soc. 131, 14196-14197.

Calderone, V., Casini, A., Mangani, S., Messori, L. \& Orioli, P. L. (2006). Angew. Chem. Int. Ed. Engl. 45, 1267-1269.

Casini, A., Gabbiani, C., Mastrobuoni, G., Messori, L., Moneti, G. \& Pieraccini, G. (2006). ChemMedChem, 1, 413-417.

Casini, A., Gabbiani, C., Mastrobuoni, G., Pellicani, R. Z., Intini, F. P., Arnesano, F., Natile, G., Moneti, G., Francese, S. \& Messori, L. (2007). Biochemistry, 46, 12220-12230.
Casini, A., Guerri, A., Gabbiani, C. \& Messori, L. (2008). J. Inorg. Biochem. 102, 995-1006.

Casini, A., Mastrobuoni, G., Temperini, C., Gabbiani, C., Francese, S., Moneti, G., Supuran, C. T., Scozzafava, A. \& Messori, L. (2007). Chem. Commun., 156-158.

Cianci, M., Helliwell, J. R. \& Suzuki, A. (2008). Acta Cryst. D64, 1196-1209.

Crider, S. E., Holbrook, R. J. \& Franz, K. J. (2010). Metallomics, 2 , 74-83.

Cruickshank, D. W. J. (1999). Acta Cryst. D55, 583-601.

Dearman, R. J., Basketter, D. A. \& Kimber, I. (1998). Food Chem. Toxicol. 36, 199-207.

Emsley, P. \& Cowtan, K. (2004). Acta Cryst. D60, 2126-2132.

Farr-Jones, S., Wong, W. Y. L., Gutheil, W. G. \& Bachovchin, W. W. (1993). J. Am. Chem. Soc. 115, 6813-6819.

Feng, L., De Dille, A., Jameson, V. J., Smith, L., Dernell, W. S. \& Manning, M. C. (2004). Cancer Chemother. Pharmacol. 54, 441-448.

Fischer, S. J., Benson, L. M., Fauq, A., Naylor, S. \& Windebank, A. J. (2008). Neurotoxicology, 29, 444-452.

Hahn, M., Kleine, M. \& Sheldrick, W. (2001). J. Biol. Inorg. Chem. 6, 556-566.

Hartinger, C. G., Ang, W. H., Casini, A., Messori, L., Keppler, B. K. \& Dyson, P. J. (2006). J. Anal. At. Spectrom. 22, 960-967.

Huang, R. S., Kistner, E. O., Bleibel, W. K., Shukla, S. J. \& Dolan, M. E. (2007). Mol. Cancer Ther. 6, 31-36.

Ivanov, A. I., Christodoulou, J., Parkinson, J. A., Barnham, K. J., Tucker, A., Woodrow, J. \& Sadler, P. J. (1998). J. Biol. Chem. 273, 14721-14730.

Jacob, S. W. \& Wood, D. C. (1967). Am. J. Surg. 114, 414-426.

Jóhannesson, H., Denisov, V. P. \& Halle, B. (1997). Protein Sci. 6, $1756-1763$.

Kerrison, S. J. S. \& Sadler, P. J. (1977). J. Chem. Soc. Chem. Commun., pp. 861-863.

Kostova, I. (2006). Recent Pat. Anticancer Drug. Discov. 1, 1-22.

Leslie, A. G. W. \& Powell, H. R. (2007). Evolving Methods for Macromolecular Crystallography, edited by R. J. Read \& J. L. Sussman, pp. 41-51. Dordrecht: Springer.

Li, S. J. (2006). Biopolymers, 81, 74-80.

McCoy, A. J., Grosse-Kunstleve, R. W., Adams, P. D., Winn, M. D., Storoni, L. C. \& Read, R. J. (2007). J. Appl. Cryst. 40, 658-674.

Mickey, D. D., Carvalho, L. \& Foulkes, K. (1989). Prostate, 15, 221-232.

Peaston, A. \& Maddison, J. (2006). Aust. Vet. J. 72, 76-77.

Perkins, S. J., Johnson, L. N., Phillips, D. C. \& Dwek, R. A. (1981). Biochem. J. 193, 553-572.

Pommier, R. F., Woltering, E. A., Milo, G. \& Fletcher, W. S. (1988). Am. J. Surg. 155, 672-676.

Pope, D. C. \& Oliver, W. T. (1966). Can. J. Comp. Med. Vet. Sci. 30, 3-8.

Rhodes, G. (2005). Get To Know Histidine. http://spdbv.vital-it.ch/ TheMolecularLevel/Goodies/Get2NoHistidine.html.

Schreurs, A. M. M., Xian, X. \& Kroon-Batenburg, L. M. J. (2010). J. Appl. Cryst. 43, 70-82.

Sheldrick, G. M. (2008). Acta Cryst. A64, 112-122.

Silverman, A. P., Bu, W., Cohen, S. M. \& Lippard, S. J. (2002). J. Biol. Chem. 277, 49743-49749.

Sun, X., Tsang, C.-N. \& Sun, H. (2009). Metallomics, 1, 25-31.

Tanley, S. W. M., Schreurs, A. M. M., Helliwell, J. R. \& KroonBatenburg, L. M. J. (2012). In the press.

Vagin, A. \& Teplyakov, A. (2010). Acta Cryst. D66, 22-25.

Zimmermann, T. \& Burda, J. V. (2010). Interdiscip. Sci. 2, 98-114. 